\title{
Combination of Preoperative Haemoglobin and Albumin Levels and Lymphocyte and Platelet Counts (HALP) in Patients with Oesophageal Cancer
}

\author{
Ugur Topal ${ }^{1}$, Fatih Dal2 ${ }^{2}$,Erdogan Mutevelli Sozuer ${ }^{3}$, Muhammet Akyuz ${ }^{4}$, \\ Tutkun Talih ${ }^{5}$, Dogan Gurkan Islam ${ }^{6}$, Hizir Yakup Akyildiz ${ }^{7}$
}

1,3,7 Department of Surgical Oncology, Erciyes University Medical Faculty, Melikgazi, Kayseri, Turkey. 2, 4, 5. 6 Department of General Surgery, Erciyes University Medical Faculty, Melikgazi, Kayseri, Turkey.

\section{ABSTRACT}

\section{BACKGROUND}

It has been previously established that the Haemoglobin, Albumin, Lymphocyte, and Platelet (HALP) score has prognostic significance in many types of malignant tumors. In oesophageal cancer, the prognostic value of the HALP score is currently uncertain. Our aim in this study was to identify the prognostic significance of the HALP score in patients with curative resected oesophageal cancer.

\section{METHODS}

This is a retrospective cohort study conducted with data obtained from the hospital records. Patients who underwent curative resection due to oesophageal cancer between 2015 and 2019 were included in the study. The HALP value was calculated by dividing the multiplication of haemoglobin ( $\mathrm{g} / \mathrm{L}$ ), albumin ( $\mathrm{g} / \mathrm{L}$ ), and lymphocyte (/ L) by the platelet counts (/ L). Receiver Operating Characteristic (ROC) analysis was performed and the ROC curve was generated to create a cutoff value for the HALP score. Two groups, Group 1 (HALP low) and Group 2 (HALP high), were formed. Demographic characteristics, clinical characteristics, tumoral characteristics, postoperative results, and mean survival of the patients were compared in the groups.

\section{RESULTS}

We divided the 43 patients into two groups based on their HALP score values. Group 1 consisted of 26 patients; Group 2 consisted of 18 patients. The mean age was similar in the groups (61 vs. 63 p: 0.625). Male sex was dominant in both groups ( $69.2 \%$ vs. $77.8 \%$ p: 0.393 ). The tumor was most commonly located in the lower oesophagus (69.2\% vs. $77.8 \%$ p: 0.044). Tumor diameter was larger in Group 1 (5.3 cm vs. 3.55 $\mathrm{cm}$ p: 0.000). Histological type distribution (p: 0.380) and degree of differentiation distribution (p: 0.065) were similar in the groups. Respiratory complications were more common in Group 1 (30.8 \% vs. 11.1 \%, p: 0.007). Anastomotic leak (p: 0.133) and wound complication (p: 0.439) were similar in the groups. The mean survival time (17 months vs. 28 months, p: 0.095) and 1-year survival rates (53.8 \% vs. 66.7 $\%)$ were lower in Group 1, but there was no difference statistically. The HALP score [HR (95 \% - Cl) 3.200 (0.909 - 11.268), p: 0.47] was not an independent risk factor in univariate and multivariate analysis for survival. Having the patient's age of $>65$ years ( $p: 0.004)$, differentiation ( $p: 0.024)$, and stage 3 disease ( $p: 0.016$ ) were independent risk factors.

\section{CONCLUSIONS}

HALP score is associated with tumoral characteristics and postoperative respiratory complications in patients with oesophageal cancer who underwent curative resection. A low HALP score is associated with decreased survival rates. However, it cannot be used as a prognostic factor alone.

\section{KEY WORDS}

Oesophageal Cancer, Curative Resection, HALP score, Immunity, Nutrition
Corresponding Author:

Uğur Topal.

Department of General Surgery,

Erciyes University, Faculty of Medicine, 38030, Melilgazi / Kayseri, Turkey.

E-mail: sutopal2005@hotmail.com

DOI: $10.14260 /$ jemds $/ 2021 / 38$

How to Cite This Article:

Topal U, Dal F, Sozuer EM, et al. Combination of preoperative haemoglobin and albumin levels and lymphocyte and platelet counts (HALP) in patients with oesophageal cancer. J Evolution Med Dent Sci 2021;10(04):173-178, DOI: $10.14260 /$ jemds $/ 2021 / 38$

Submission 06-08-2020,

Peer Review 07-11-2020

Acceptance 14-11-2020,

Published 25-01-2021.

Copyright (C) 2021 Ugur Topal et al. This is an open access article distributed under Creative Commons Attribution License [Attribution 4.0 International (CC BY 4.0)] 


\section{BACKGROUND}

Oesophageal cancer is the $7^{\text {th }}$ most diagnosed malignant tumor with 572,000 new cases and is the sixth leading cause of cancer-related mortality with 509,000 deaths worldwide, according to 2018 statistics. ${ }^{1}$ Despite improvements in surgical techniques, preoperative and postoperative care and conditions, oesophageal cancer still has a high mortality rate and poor prognosis. The overall 5-year survival rate for patients is less than $20 \% .^{2}$ Knowing the prognostic factors in oesophageal cancer is of importance in predicting responses to treatment and individualizing the choice of treatment modality. With scientific advances, a wide variety of new molecular markers and their combination have started to be used to predict the prognosis in oesophageal cancer.3-8

Nutritional deficiencies are common in gastrointestinal system malignancies, especially oesophageal cancer and sometimes the most important problem in this group may be to overcome malnutrition. ${ }^{9}$

Systemic inflammation and nutritional status have drawn interest increasingly in many malignancies. ${ }^{10,11}$ It has been shown that in the development and progression of various cancers, including oesophageal cancer, systemic inflammation and nutritional status play important roles. ${ }^{12}$ Increased systemic inflammation and malnutrition are reported to be associated with poor prognosis. 4,6 The nutritional or immune status of the host can be evaluated by hematological examination and many hematological indices have been demonstrated to have prognostic value in various cancers. ${ }^{4,10,11}$

In recent studies, it was reported that HALP, a new composite index was associated with the survival of patients in gastric cancer, ${ }^{13,14}$ pancreatic cancer, ${ }^{15}$ colorectal cancer, ${ }^{16}$ bladder cancer ${ }^{17}$ and renal cancer. ${ }^{18}$ In oesophageal cancer, it has been suggested that pretreatment HALP score can be used to predict the response to platinum-based chemo radiotherapy and progression-free survival in male patients with Oesophageal Squamous Cell Carcinoma (ESCC). ${ }^{4}$ The value of the HALP score in patients with oesophageal cancer who underwent curative surgical resection in the literature remains uncertain.

In our study, we tried to determine the prognostic significance of the combination of preoperative haemoglobin and albumin levels and the lymphocyte and platelet counts (HALP), and their correlation with postoperative complications in patients with oesophageal cancer who underwent curative resection.

\section{METHODS}

This is a retrospective cohort study from the hospital records. After obtaining the approval of the Local Ethics Committee of Erciyes University Faculty of Medicine dated 24.06.2020 and numbered 2020 / 329 52, patients who underwent curative surgical resection for oesophageal cancer between January 2015 and January 2019 were included in the study. 8 patients undergoing palliative surgery, patients with Stage 4 disease, patients under the age of eighteen, pregnant patients, patients with chronic inflammatory (tuberculosis, sarcoidosis, etc.) and autoimmune diseases, patients with haematological diseases, patients using steroids, and patients whose records could not be accessed were excluded from the study The remaining 44 patients were included in the study. A common database was created prospectively by examining patient files and hospital information system records. Patients were analyzed retrospectively using this database.

Blood samples were collected when the patients were hospitalized for surgery. The complete blood count was measured by an automated haematology analyser (Roche Hitachi Cobas ${ }^{\circledR} 8000$ Roche Diagnostics, Indianapolis, IN, USA). While calculating the HALP index, haemoglobin (g / L), albumin (g / L), lymphocytes (/ L), platelets (/ L) unit conversions were made in normal value units. Then, the HALP index was calculated by the following formula: haemoglobin ( $g$ / L) $\times$ albumin (g / L) $\times$ lymphocytes (/ L) / platelets (/ L).

In the study, the cutoff value was determined by calculating the sensitivity and specificity values for the HALP value based on overall survival and examining the area under the ROC curve. After the cut-off value was determined by ROC curves, we divided the patients into two groups according to the cut-off value as Group 1 (low HALP) and Group 2 (high HALP). Demographic and clinical data, American Society of Anesthesiologists (ASA) score, Body Mass Index (BMI), preoperative laboratory values, tumor localizations, operative (duration, anastomosis technique, blood loss) variables, tumoral characteristics including diameter, histological type, degree of differentiation, pathological stage, and the number of lymph nodes dissected, respiratory complications, complications related to wound and anastomosis, and postoperative complication status according to Clavien-Dindo classification from the postoperative follow-up data, ${ }^{19}$ duration of hospital stay, 90-day re-admission causes and current clinical status, postoperative 90 -day mortality rates, and mean survival of the patients were compared between the two groups.

Anastomotic leak was defined as a disruption in the integrity of the anastomosis documented by the combination of clinical, radiological, and operative tools. Wound infection was defined by the Centers for Disease Control (CDC) as superficial or deep surgical site infections occurring in the surgical wound. ${ }^{20}$

Tumor-Node-Metastasis (TNM) classification system (2010 and 2016) was used for tumor staging.

\section{Statistical Analysis}

The statistical analysis of the data obtained in this study was performed with the SPSS (Statistical Package for the Social Sciences) 23.0 package program. Categorical measurements were summarized as numbers and percentages, while continuous measurements were summarized as mean and standard deviation (median and minimum-maximum, where necessary). Pearson chi-square test statistics was used for the comparison of categorical variables. Shapiro-Wilk test was used to determine whether the parameters in the study showed normal distribution. For comparisons of the continuous measurements between the groups, the distributions were controlled and independent student t-test was used for the parameters with normal distribution, and Mann Whitney $\mathrm{u}$ tests for the parameters without normal distribution. T Kaplan-Meier analysis and Log Rank tests were used for survival analyses. The significance level was considered to be 0.05 for all tests. 


\section{RESULTS}

In our study, a total of 44 patients were included. To confirm the HALP cutoff value, we used the receiver operating characteristic curve (Graph 1). The patients were divided into two groups based on the cutoff value of 43: Group 1 (low HALP) and Group 2 (high HALP). Group 1 consisted of 26 patients and Group 2 consisted of 18 patients.

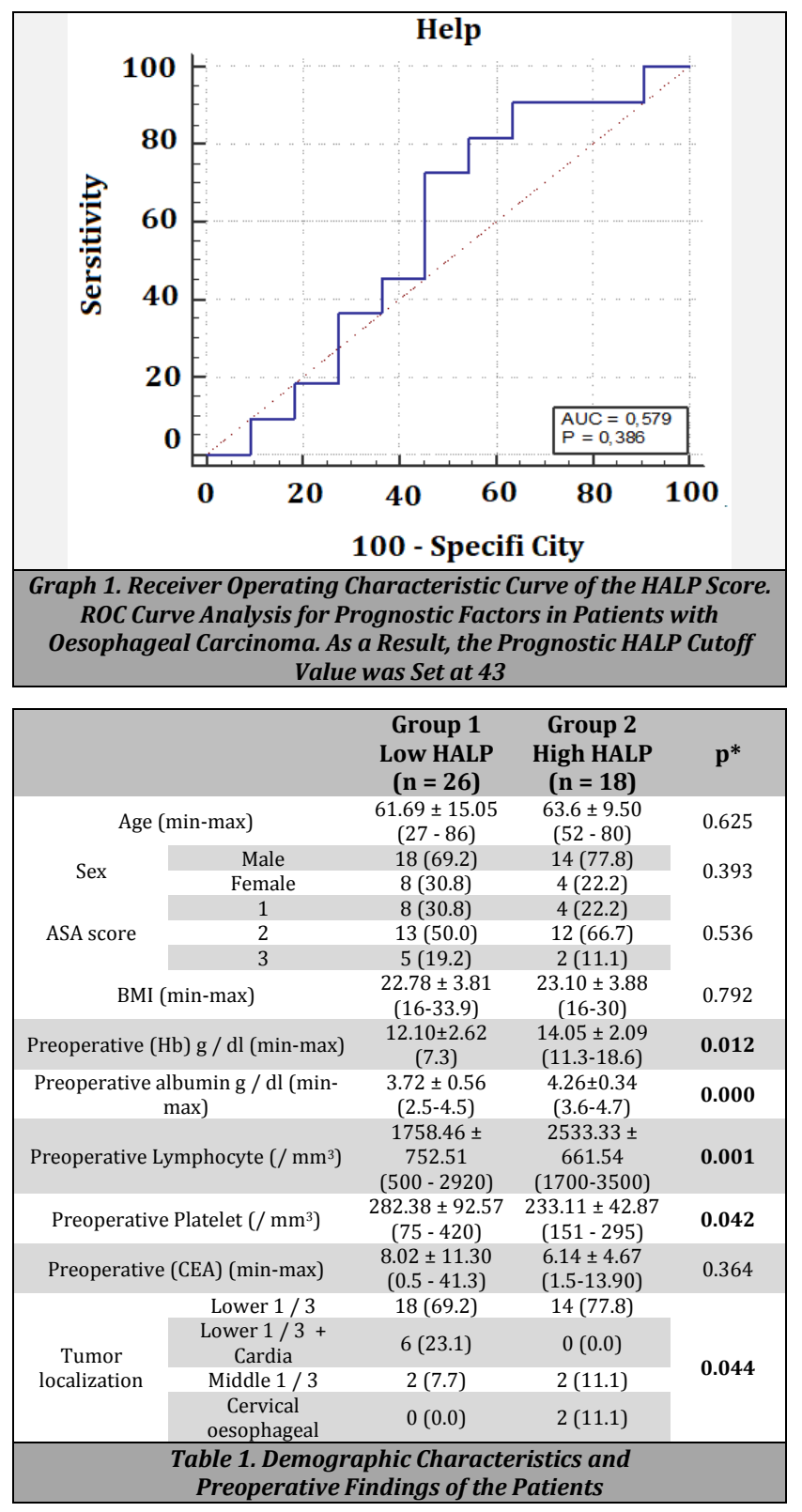

The mean age was similar in groups (61 vs. 63 p: 0.625 ). Male sex was dominant in both groups (69.2\% vs. $77.8 \%$ p: 0.393). ASA scores were predominantly 2 (50 \% vs. $66.7 \%$ p: 0.536). BMI was similar (22 vs. 23 p: 0.792). While preoperative $\mathrm{Hb}$ (12 vs. 14 p: 0.012 ), albumin (3.7 vs. 4.2 p: 0.00 ), and lymphocyte counts (1758 vs. 2533 p: 0.001 ) were lower in Group 1, platelet counts were lower in Group 2 (282.000 vs. 233.000 p: 0.042). CEA (Carcino-Embryonic Antigen) levels were similar (8.02 vs. 6.14 p: 0.364). Tumours were most commonly located in the lower oesophagus in both groups (69.2 \% vs. $77.8 \%$ p: 0.044). Demographic and clinical characteristics are shown in (Table 1).

\begin{tabular}{|c|c|c|c|c|}
\hline & & $\begin{array}{l}\text { Group } 1 \\
\text { Low HALP } \\
(\mathrm{n}=26)\end{array}$ & $\begin{array}{c}\text { Group } 2 \\
\text { High HALP } \\
\text { (n= 18) }\end{array}$ & $\mathbf{p}^{*}$ \\
\hline $\begin{array}{l}\text { Anastomosis } \\
\text { Technique }\end{array}$ & $\begin{array}{l}\text { Handsewn } \\
\text { Stapler }\end{array}$ & $\begin{array}{c}6(23.1) \\
20(76.9)\end{array}$ & $\begin{array}{c}4(22.2) \\
14(77.8)\end{array}$ & 0.621 \\
\hline \multicolumn{2}{|c|}{ Duration of surgery (min-max) } & $\begin{array}{c}280.0 \pm 91.46 \\
(140-450)\end{array}$ & $\begin{array}{c}259.44 \pm 73.74 \\
(150-420)\end{array}$ & 0.458 \\
\hline \multicolumn{2}{|c|}{$\begin{array}{l}\text { Intraoperative blood loss } \\
\text { (min-max) }\end{array}$} & $\begin{array}{l}211.15 \pm 127.76 \\
(10-600)\end{array}$ & $\begin{array}{l}261.66 \pm 206.29 \\
\quad(10-600)\end{array}$ & 0.800 \\
\hline \multicolumn{2}{|c|}{ Intraoperative complication } & $0(0.0)$ & $2(11.1)$ & 0,082 \\
\hline \multicolumn{2}{|c|}{ Tumor diameter (min-max) } & $\begin{array}{l}5.38 \pm 1.59 \\
(3.5-9.0)\end{array}$ & $\begin{array}{c}3.55 \pm 1.28 \\
(1.50-5.25)\end{array}$ & 0.000 \\
\hline $\begin{array}{l}\text { Histological } A \\
\text { type }\end{array}$ & $\begin{array}{l}\text { Adenocarcinoma } \\
\text { SCC }\end{array}$ & $\begin{array}{l}12(46.2) \\
14(53.8)\end{array}$ & $\begin{array}{l}10(55.6) \\
8(44.4)\end{array}$ & 0.380 \\
\hline \multirow{2}{*}{ Differentiation } & $\begin{array}{l}\text { High grade } \\
\text { Low grade }\end{array}$ & $\begin{array}{c}10(38.5) \\
2(7.7)\end{array}$ & $\begin{array}{l}8(44.4) \\
4(22.2)\end{array}$ & \multirow{2}{*}{0.065} \\
\hline & $\begin{array}{l}\text { Middle grade } \\
\text { Signet-ring }\end{array}$ & $\begin{array}{c}14(53.8) \\
0(0.0)\end{array}$ & $4(22.2)$ & \\
\hline \multirow{3}{*}{ Pathological T } & $\mathrm{T} 1$ & $2(7.7)$ & $2(11.1)$ & \multirow{3}{*}{0.307} \\
\hline & T2 & 4 (15.4) & $6(33.3)$ & \\
\hline & $\begin{array}{l}\text { T3 } \\
\text { T4 }\end{array}$ & $\begin{array}{c}16(61.5) \\
4(15.4)\end{array}$ & $\begin{array}{l}6(33.3) \\
4(22.2)\end{array}$ & \\
\hline \multirow{2}{*}{ Pathological N } & No & $2(7.7)$ & $4(22.2)$ & \multirow{2}{*}{0.175} \\
\hline & N1 & $24(92.3)$ & $14(77.8)$ & \\
\hline \multirow{4}{*}{$\begin{array}{l}\text { Pathological } \\
\text { TNM }\end{array}$} & Stage 1B & 4 (15.4) & $4(22.2)$ & \multirow{4}{*}{0.699} \\
\hline & Stage 2B & $4(15.4)$ & $4(22.2)$ & \\
\hline & Stage 3A & $2(7.7)$ & $2(11.1)$ & \\
\hline & Stage 3B & $16(61.5)$ & $8(44.4)$ & \\
\hline \multicolumn{2}{|c|}{$\begin{array}{l}\text { Total lymph node dissected } \\
\text { (min-max) }\end{array}$} & $\begin{array}{c}23.61 \pm 8.29 \\
(12-43)\end{array}$ & $\begin{array}{c}33.11 \pm 10.49 \\
(22-52)\end{array}$ & 0.004 \\
\hline \multicolumn{2}{|c|}{$\begin{array}{c}\text { Number of metastatic lymph } \\
\text { nodes }\end{array}$} & $\begin{array}{c}5.76 \pm 5.10 \\
(0-18)\end{array}$ & $\begin{array}{c}7.0 \pm 6.11 \\
(0-18)\end{array}$ & 0.631 \\
\hline \multicolumn{5}{|c|}{ Table 2. Intraoperative and Tumoral Characteristics } \\
\hline
\end{tabular}

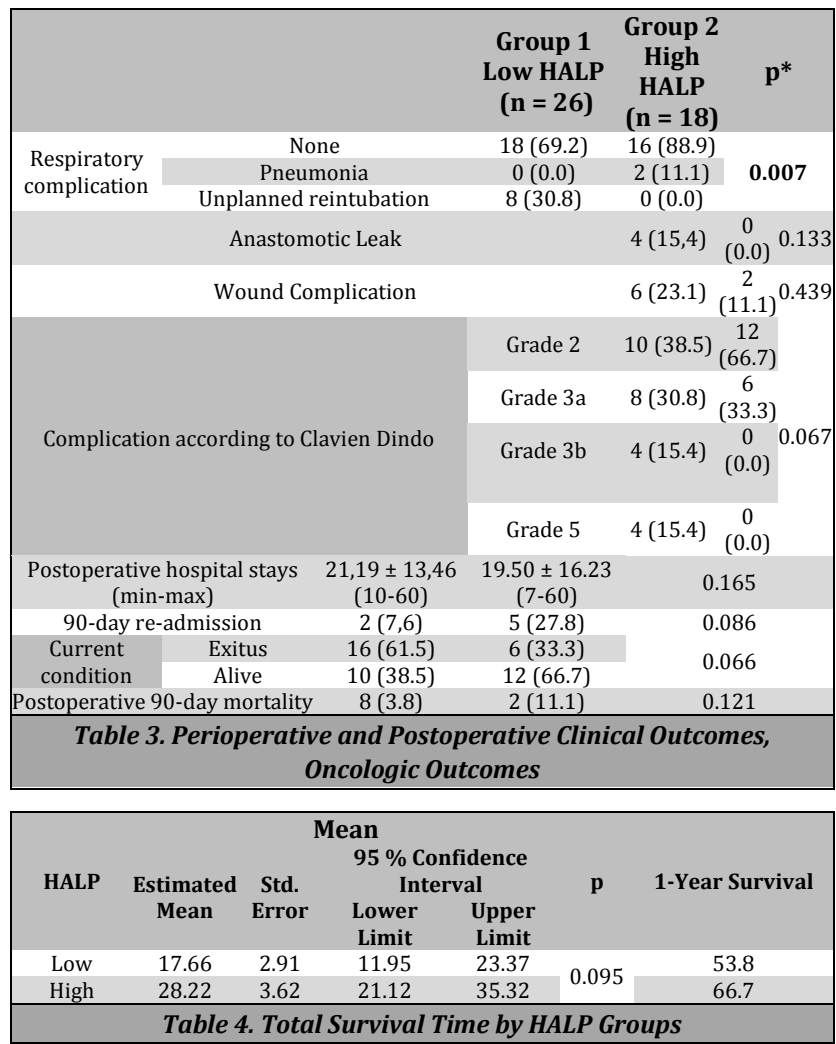

No differences were seen between the groups in terms of anastomosis technique (p: 0.533 ), duration of surgery (280 vs. 259, p: 0.458), intraoperative blood loss ( $211 \mathrm{ml} v \mathrm{vs} .261 \mathrm{ml}$, p: 0.800 ), and the presence of intraoperative complications ( $\mathrm{p}$ : 0.082). Intraoperative characteristics are shown in (Table 2). 


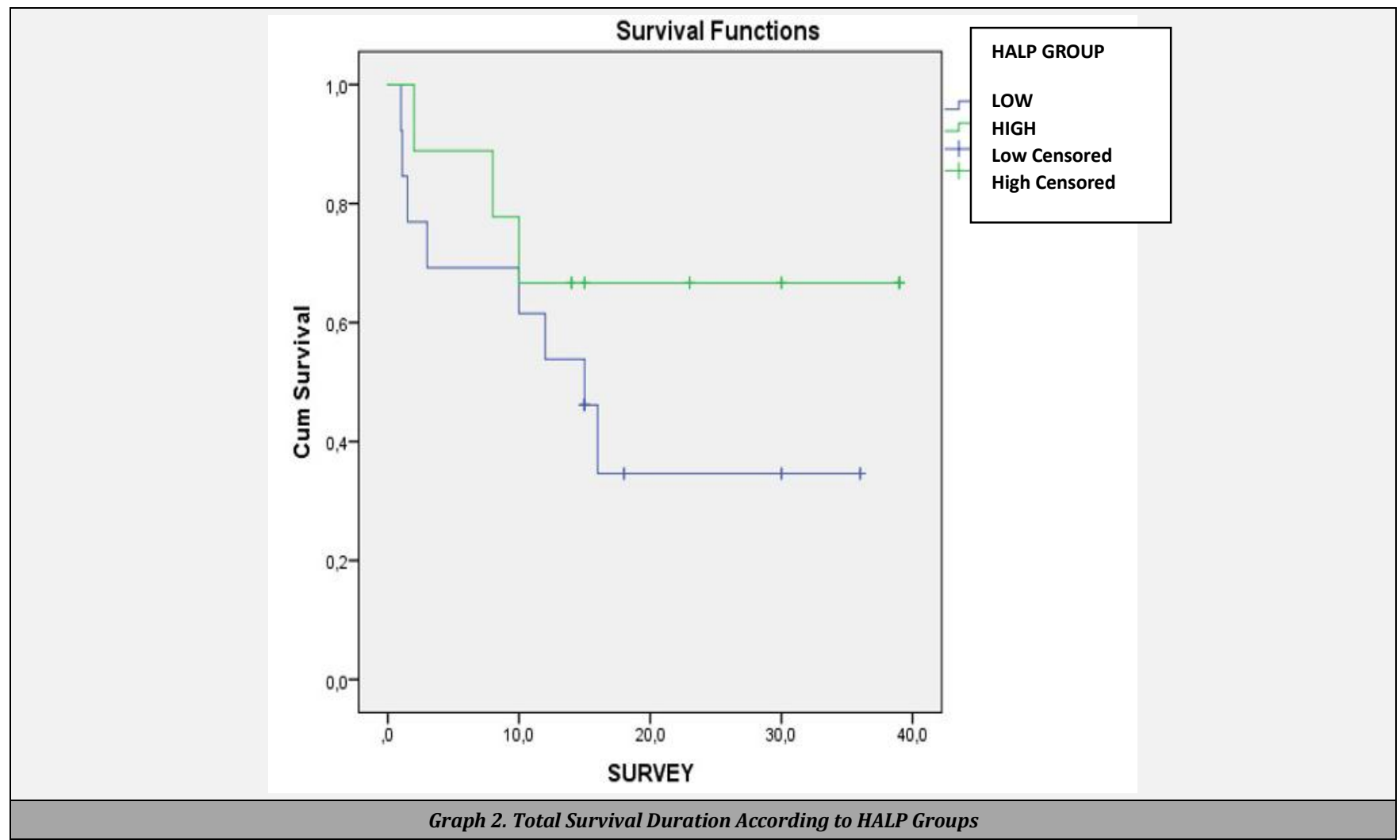

\begin{tabular}{|c|c|c|c|c|}
\hline \multicolumn{2}{|c|}{ Measurements } & Univariate & \multirow[b]{2}{*}{$\begin{array}{c}1.000 \\
0.141(0.037-0.530)\end{array}$} & \multirow[b]{2}{*}{0.004} \\
\hline Age & $\begin{array}{l}<65 \\
\geq 65\end{array}$ & 0.002 & & \\
\hline Sex & $\begin{array}{l}\text { Female } \\
\text { Male }\end{array}$ & 0.005 & $\begin{array}{c}1.000 \\
8.333(1.556-44.642)\end{array}$ & 0.013 \\
\hline Asa score & $\begin{array}{c}1-2 \\
3\end{array}$ & 0.680 & $\begin{array}{c}1.000 \\
1.407(0.276-7.182)\end{array}$ & 0.681 \\
\hline Tumor diameter & $\begin{array}{l}<5 \\
>5\end{array}$ & 1.000 & $\begin{array}{c}1.000 \\
1.000(0.293-3.416)\end{array}$ & 1.000 \\
\hline Albumin & $\begin{array}{l}<3.5 \\
>3.5\end{array}$ & 0.471 & $\begin{array}{c}1.000 \\
1.687(0.403-7.074)\end{array}$ & 0.474 \\
\hline \multirow[t]{2}{*}{ BMI } & $\begin{array}{l}<20 \\
20-25\end{array}$ & \multirow[t]{2}{*}{0.181} & $\begin{array}{c}1.000 \\
0.381(0.082-1.768)\end{array}$ & $\begin{array}{l}0.195 \\
0.218\end{array}$ \\
\hline & $>25$ & & $1.333(0.233$ - 7.626$)$ & 0.746 \\
\hline \multirow{3}{*}{ Differentiation } & High & \multirow{3}{*}{0.000} & & 0.024 \\
\hline & Low & & $1.292(0.897-2.344)$ & 0.999 \\
\hline & $\begin{array}{l}\text { Middle } \\
\text { T1 }\end{array}$ & & $\begin{array}{c}16.000(27.34-93.623) \\
1.000\end{array}$ & $\begin{array}{l}\mathbf{0 . 0 0 2} \\
0.119\end{array}$ \\
\hline \multirow{3}{*}{$\mathrm{T}$} & $\mathrm{T} 2$ & \multirow{3}{*}{0.754} & $0.012(0.009-0.173)$ & 0.912 \\
\hline & T3 & & $0.037(0.011-0.139)$ & 0.946 \\
\hline & $\mathrm{T} 4$ & & $0.141(0.000-0.000)$ & 0.978 \\
\hline $\mathrm{N}$ & $\begin{array}{l}\text { N0 } \\
\text { N1 }\end{array}$ & 0.622 & $\begin{array}{c}1.000 \\
0.022(0.010-0.103)\end{array}$ & 0.963 \\
\hline \multirow{2}{*}{$\begin{array}{l}\text { Pathological } \\
\text { TNM }\end{array}$} & Stage 1-2 & 0.011 & $\begin{array}{c}1.000 \\
0185(0.047-0729)\end{array}$ & 0.016 \\
\hline & $\begin{array}{l}\text { Stage } 3 \\
\text { Lower } 1 / 3\end{array}$ & \multirow{4}{*}{0.541} & $\begin{array}{c}0.185(0.047-0.729) \\
1.000\end{array}$ & 1.000 \\
\hline \multirow{3}{*}{$\begin{array}{c}\text { Tumor } \\
\text { localization }\end{array}$} & Lower $1 / 3+$ Cardia & & $1.202(0.872-1.657)$ & 0.745 \\
\hline & Middle 1 / 3 & & $1.305(0.953-1.795)$ & 0.673 \\
\hline & Cervical oesophageal & & $1.418(0.788-1.863)$ & 0.544 \\
\hline Anastomotic leak & $\begin{array}{l}\text { Present } \\
\text { Phsent }\end{array}$ & 0.169 & $\begin{array}{c}1.000 \\
1247(0798-1843)\end{array}$ & 0.765 \\
\hline \multirow{2}{*}{ HALP } & $\begin{array}{l}\text { Ausent } \\
<43\end{array}$ & \multirow{2}{*}{0.064} & & \\
\hline & $>43$ & & $3.200(0.909-11.268)$ & 0.070 \\
\hline
\end{tabular}

Tumour diameter was larger in Group 1 (5.3 cm vs. 3.55 cm p: 0.000). No significant differences were seen between the two groups in terms of histological type distribution ( $p: 0.380$ ) and degree of differentiation distribution (p: 0.065), pathological T stage (p: 0.307), and N stage (p: 0.175). Stage 3 B tumor was found most commonly in both groups. (61.5\% vs. $44 \%$ p: 0.699). The number of metastatic lymph nodes was higher in Group 2 (5.76 vs. 7 p: 0.631). Pathological characteristics are shown in (Table 2).
Respiratory complications were higher in Group 1 (30.8\% vs. $11.1 \%$, p: 0.007). There was no significant difference between the two groups regarding anastomotic leak (p: 0.133), wound complication ( $\mathrm{p}$ : 0.439), complication distribution according to Clavien Dindo (p: 0.067), postoperative hospital stay ( 21 vs. 19 p: 0.165 ), 90-day readmission rates ( $7.6 \%$ vs. $27.8 \%$ p: 0.086 ), and postoperative 90-day mortality (30.8 \% vs. $11 \%$ p: 0.112). Postoperative results are shown in (Table 3 ).

The mean survival time (17 months vs. 28 months, p: 0.095 ) and 1-year survival rates (53.8 \% vs. $66.7 \%$ ) were lower in Group 1, however, there was no difference statistically. It is shown in (Graph 2) and (Table 4).

In univariate and multivariate analysis for survival, the HALP score (HR (95 \% - Cl) 3.200 (0.909 - 11.268), p: 0.47) was not an independent risk factor. Having the patient's age of $>65$ years (p: 0.004), degree of differentiation (p: 0.024), and Stage 3 disease (p: 0.016) were independent risk factors. It is shown in (Table 5).

\section{DISCUSSION}

Malnutrition and systemic inflammation are considered to be important components of cancer. In this study, based on the preoperative haemoglobin, albumin, lymphocyte, and platelet values, a new HALP index, which is considered to be potentially used in the prognostic prediction of oesophageal cancer, was generated. In our study, we found that tumour size and localization of HALP was associated with postoperative respiratory complications. There was no statistical difference, although the mean survival time and 1-year survival were lower in the group with a low HALP score. This may be related to the limited number of patients in the study. 
Systemic inflammation stimulates immunosuppression and angiogenesis, increasing microenvironment formation that can promote the initiation of tumour cells, their progression, and metastasis. ${ }^{21,22}$ The function of lymphocytes is to stimulate cytokine production and the death of cytotoxic cells that inhibit cancer development. ${ }^{23}$ It has been shown that the frequency of metastasis decreases and the prognosis of patients improves with intensive intratumoural lymphocytic infiltration in early lesions. ${ }^{24}$ Platelets can protect cancer cells by platelet-mediated protective effects in blood cells. Some reports have shown that platelets play a role in the growth, protection, tumour angiogenesis, and metastasis of cancer cells by promoting the release of many types of plateletderived endothelial cell growth factors. ${ }^{25,26}$ Anaemia is a commonly seen symptom in cancer patients. Low haemoglobin level is associated with a poor response to treatment and impairs survival, especially in patients with the advanced stage of the disease. ${ }^{15,27}$ Serum albumin levels can give an idea about the long-term nutritional status retrospectively. In advanced cancer patients, protein synthesis reduces and albumin levels decrease. This is the main cause of the occurrence of sarcopenia among cancer patients with a high tumour load. Low albumin levels have previously been associated with reduced survival and increased risk of complications in oesophageal cancer. ${ }^{27-29}$

Haematological indices generated based on this evidence have been promising in predicting the prognosis of cancer patients and postoperative poor results, but a single index may not have sufficient predictive power for clinical practice. Joint analysis of multiple markers may increase predictive power. ${ }^{3-}$ 6,10 The HALP score can be seen as a comprehensive index, which reflects components of the immune and nutritional status of patients and has been shown to play a prognostic role in various gastrointestinal cancers. $4,13,16$

Cong, $\mathrm{L}$ et al found that HALP is significant in predicting tumour response in their study where they examine whether the HALP score measurement could be an effective parameter in predicting response to platinum-based definitive chemo radiotherapy and prognosis in patients with oesophageal squamous cell carcinoma $(p=0.010)$. A difference in median progression-free survival was found between the patient groups with low HALP and high HALP (10.7 vs. 24.7 months, p $=0.041$ ). When multivariate analysis was performed, patients with a HALP value of $>48.34$ had longer progression-free survival when compared to patients with a HALP value of $\leq$ 48.34 (HR 2.745; 95 \% CI, 1.176 - 6.408; $\mathrm{p}=0.020$ ). Although, no significant difference in overall survival was observed between the two groups. Besides, no significant difference was observed between the groups with low HALP and high HALP levels in terms of toxicity due to acute treatment other than nausea. In their studies, there was no correlation between HALP score and demographic characteristics, tumour length, tumour localization, and stage. 4

In our study, unlike the study of Cong, L et al., patients who underwent curative surgery and histological type of adenocarcinoma were included. Also, in our study, the ROC curves were used when determining cutoff for the HALP score. As expected, the parameters that constituted the HALP score have differences between the HALP groups. The HALP score was higher in tumours with proximal localization. This may be related to the difference in nutritional status and tumour localization. Operative variables were not different in groups. In the Group with low HALP, the tumour diameter was larger, which may be secondary to increased tumour diameter and associated malnutrition and increased inflammatory response. Our tumour stages were not related to the HALP score. In particular, postoperative respiratory complications were higher in the group with low HALP and accordingly, 90day mortality rates were higher in the group with low HALP. Similar to the study of Cong, L et al., the mean survival and 1year survival were lower in the group with low HALP, but this was not found to be statistically significant. This may be because of the small number of patients. As expected in the analysis of independent factors related to survival, age and gender of patient, and degree of differentiation and stage among the tumoural characteristics were found to be significant. The HALP score was not an independent variable for survival.

As far as we have researched, our study is the first in the literature to evaluate the prognostic value of HALP levels of patients with oesophageal cancer treated with curative surgical resection. Our study has certain limitations. First, there is no consensus on the cutoff value for HALP and studies investigating HALP are rare. In addition, we had a limited number of patients in our study.

\section{CONCLUSIONS}

HALP score is closely related to the diameter of the tumour, postoperative respiratory complications, and the number of lymph nodes dissected in oesophageal cancer. It cannot be used alone in predicting prognosis in oesophageal cancer for which curative resection is performed. The use of HALP in clinical practice to drive individual therapeutic strategies for treatment in patients with oesophageal cancer is limited. Multicenter studies with a large patient population are needed in this regard.

Data sharing statement provided by the authors is available with the full text of this article at jemds.com.

Financial or other competing interests: None.

Disclosure forms provided by the authors are available with the full text of this article at jemds.com.

\section{REFERENCES}

[1] Bray F, Ferlay J, Soerjomataram I, et al. Global cancer statistics 2018: GLOBOCAN estimates of incidence and mortality worldwide for 36 cancers in 185 countries. CA Cancer J Clin 2018;68(6):394-424.

[2] Siegel R, Ma J, Zou Z, et al. Cancer statistics, 2014. CA Cancer J Clin 2014;64(1):9-29.

[3] Dal F, Topal U, Sozuer E, et al. Prognostic significance of the neutrophil to lymphocyte ratio in patients with curative resection of oesophageal cancer: a single center experience. Ann Ital Chir 2020;9:S0003469X20032716.

[4] Cong $\mathrm{L}, \mathrm{Hu} \mathrm{L}$. The value of the combination of haemoglobin, albumin, lymphocyte and platelet in predicting platinum-based chemoradiotherapy response in male patients with oesophageal squamous cell carcinoma. Int Immunopharmaco 2017;46:75-9.

[5] Xiao FK, Wang L, Zhang WC, et al. Preoperative prognostic nutritional index is a significant predictor of survival in 
oesophageal squamous cell carcinoma patients. Nutr Cancer 2020: p. 1-6.

[6] Zhou N, Hofstetter WL. Prognostic and therapeutic molecular markers in the clinical management of oesophageal cancer. Expert Rev Mol Diagn 2020;20(4):401-11.

[7] Im WR, Lee HS, Lee YS, et al. A regulatory noncoding RNA, nc886, suppresses oesophageal cancer by inhibiting the AKT pathway and cell cycle progression. Cells 2020:9(4):801.

[8] Li M, Wang K, Pang Y, et al. Secreted phosphoprotein 1 (SPP1) and fibronectin 1 (FN1) are associated with progression and prognosis of oesophageal cancer as identified by integrated expression profiles analysis. Med Sci Monit 2020;26:e920355.

[9] Pennathur A, Gibson MK, Jobe BA, et al. Oesophageal carcinoma. Lancet 2013;381(9864):400-12.

[10] Yalav 0, Topal U, Unal AG. Clinical value of neutrophil / lymphocyte ratio in predicting postoperative complications, lymph node positivity and prognosis in gastric cancer patients who underwent curative surgical resection. Ann Med Res 2019;26(11):2513-9.

[11] Yalav O, Topal U, Ünal AG, et al. Clinical value of neutrophil /lymphocyte ratio in predicting postoperative complications and prognosis in patients with colorectal cancer undergoing surgical treatment. Turk J Colorectal Dis 2020;30(11):49-56.

[12] McMillan DC. Systemic inflammation, nutritional status and survival in patients with cancer. Curr Opin Clin Nutr Metab Care 2009;12(3):223-6.

[13] Chen XL, Xue L, Wang W, et al. Prognostic significance of the combination of preoperative haemoglobin, albumin, lymphocyte and platelet in patients with gastric carcinoma: a retrospective cohort study. Oncotarget 2015;6(38):41370-82.

[14] Yalav O, Topal U, Ünal AG, et al. Clinical value of haemoglobin and albumin levels and lymphocyte and platelet count (HALP) combination in predicting postoperative complications, lymph node positivity and prognosis in gastric cancer patients who underwent curative surgical resection. Cyprus J Med Sci 2020;5(2):145-52.

[15] Xu SS, Li S, Xu HX, et al. Haemoglobin, albumin, lymphocyte and platelet predicts postoperative survival in pancreatic cancer. World J Gastroenterol 2020;26(8):828-38.

[16] Jiang $\mathrm{H}$, Li H, Li A, et al. combined haemoglobin, albumin, lymphocyte and platelet levels predict survival in patients with locally advanced colorectal cancer. Oncotarget 2016;7(44):72076-83.

[17] Peng D, Zhang CJ, Gong YQ, et al. Prognostic significance of HALP (haemoglobin, albumin, lymphocyte and platelet) in patients with bladder cancer after radical cystectomy. Sci Rep 2018;8(1):794.

[18] Peng D, Zhang CJ, Tang Q, et al. Prognostic significance of the combination of preoperative haemoglobin and albumin levels and lymphocyte and platelet counts (HALP) in patients with renal cell carcinoma after nephrectomy. BMC Urol 2018;18(1):20.

[19] Clavien PA, Barkun J, de Oliveira ML, et al. The claviendindo classification of surgical complications: five-year experience. Ann Surg 2009;250(2):187-96.

[20] Horan TC, Gaynes RP, Martone WJ, et al. CDC definitions of nosocomial surgical site infections, 1992: a modification of CDC definitions of surgical wound infections. Infect Control Hosp Epidemiol 1992;13(10):606-8.

[21] Greten FR, Grivennikov SI. Inflammation and cancer: triggers, mechanisms and consequences. Immunity 2019;51(1):27-41.

[22] Shalapour S, Karin M. Pas de deux: control of anti-tumor immunity by cancer-associated inflammation. Immunity 2019;51(1):15-26.

[23] Terzic J, Grivennikov S, Karin E, et al. Inflammation and colon cancer. Gastroenterology 2010;138(6):2101-14.

[24] Zhang L, Conejo-Garcia JR, Katsaros D, et al. Intratumoral $\mathrm{T}$ cells, recurrence and survival in epithelial ovarian cancer. N Engl J Med 2003;348(3):203-13.

[25] Stegner D, Dütting S, Nieswandt B. Mechanistic explanation for platelet contribution to cancer metastasis. Thromb Res 2014;133(Suppl 2):S149-57.

[26] Takahashi Y, Bucana CD, Akagi Y, et al. Significance of platelet-derived endothelial cell growth factor in the angiogenesis of human gastric cancer. Clin Cancer Res 1998;4(2):429-34.

[27] McGrane JM, Humes DJ, Acheson AG, et al. Significance of anemia in outcomes after neoadjuvant chemoradiotherapy for locally advanced rectal cancer. Clin Colorectal Cancer 2017;16(4):381-5.

[28] Miranda-Goncalves V, Lameirinhas A, Henrique R, et al. Metabolism and epigenetic interplay in cancer: regulation and putative therapeutic targets. Front Genet 2018;9:427.

[29] Goh SL, De Silva RP, Dhital K, et al. Is low serum albumin associated with postoperative complications in patients undergoing oesophagectomy for oesophageal malignancies? Interact Cardiovasc Thorac Surg 2015;20(1):107-13. 